\title{
Post-epizootic chronic dolphin morbillivirus infection in Mediterranean striped dolphins Stenella coeruleoalba
}

\author{
Sara Soto ${ }^{1, *}$, Ana Alba ${ }^{1}$, Llilianne Ganges ${ }^{1}$, Enric Vidal ${ }^{1}$, Juan Antonio Raga ${ }^{2}$, \\ Ferrán Alegre $^{3}$, Beatriz González ${ }^{3}$, Pascual Medina ${ }^{3}$, Irene Zorrilla ${ }^{4}$, \\ Jorge Martínez ${ }^{5}$, Alberto Marco ${ }^{5}$, Mónica Pérez ${ }^{1}$, Blanca Pérez ${ }^{5}$, \\ Ana Pérez de Vargas Mesas ${ }^{4}$, Rosa Martínez Valverde ${ }^{4}$, Mariano Domingo ${ }^{1,5}$ \\ ${ }^{1}$ CRESA (Centre de Recerca en Sanitat Animal), Campus Universitat Autònoma de Barcelona (UAB), \\ 08193 Bellaterra-Barcelona, Spain \\ ${ }^{2}$ Institut Cavanilles de Biodiversitat i Biologia Evolutiva, Parc Científic, Universitat de València, Catedrático José Beltrán 2 , \\ 46980 Paterna (Valencia), Spain \\ ${ }^{3}$ CRAM (Fundació per la Conservació y Recuperació d'Animals Marins), Carretera de la Platja 28-30, \\ 08820 El Prat de Llobregat-Barcelona, Spain \\ ${ }^{4}$ EGMASA-Centro de Análisis y Diagnóstico de la Fauna Silvestre-C.A.D., 29010 Málaga, Spain \\ ${ }^{5}$ Departament de Sanitat i d'Anatomia Animals, Facultat de Veterinària, Universitat Autònoma de Barcelona (UAB), \\ 08193 Bellaterra-Barcelona, Spain
}

\begin{abstract}
Dolphin morbillivirus (DMV) has caused 2 epizootics with high mortality rates on the Spanish Mediterranean coast, in 1990 and 2006-07, mainly affecting striped dolphins Stenella coeruleoalba. Following the first epizootic unusual DMV infections affecting only the central nervous system of striped dolphins were found, with histological features similar to subacute sclerosing panencephalitis and old dog encephalitis, the chronic latent localised infections caused by defective forms of measles virus and canine distemper virus, respectively. Between 2008 and 2010, monitoring by microscopic and immunohistochemical (IHC) studies of 118 striped dolphins stranded along Catalonia, the Valencia Region and Andalusia showed similar localised DMV nervous system infections in 25.0, 28.6 and $27.4 \%$ of cases, respectively, with no significant differences among regions or sex. The body length of DMV-infected dolphins was statistically greater than that of non-infected dolphins (196.5 vs. $160.5 \mathrm{~cm} ; \mathrm{p}<0.001)$. Molecular detection of DMV was performed by 2 different RT-PCR techniques amplifying a $429 \mathrm{bp}$ fragment and a $78 \mathrm{bp}$ fragment both within the phosphoprotein (P) gene. The $429 \mathrm{bp}$ RT-PCR results contradicted the IHC-DMV results as only 3 of 6 dolphins with positive IHC-DMV had positive PCR results. All 6 cases were positive with the $78 \mathrm{bp}$ RT-PCR. These findings contraindicate the use of the $429 \mathrm{bp}$ RT-PCR protocol based on the P gene to detect this specific form of DMV. DMV localised nervous infection constitutes the most relevant single cause of stranding and death in Mediterranean striped dolphins in the years following a DMV epizootic, and it might even overwhelm the effects of the epizootic itself, at least in 2007.
\end{abstract}

KEY WORDS: Dolphin morbillivirus - Striped dolphin · Stenella coeruleoalba - Encephalitis · Subacute sclerosing panencephalitis $\cdot$ SSPE $\cdot$ Localised form $\cdot$ Mediterranean Sea 


\section{INTRODUCTION}

Two dolphin morbillivirus (DMV) epizootics starting in 1990 and 2006-07 have caused massive dieoffs of Mediterranean striped dolphins Stenella coeruleoalba, as well as of other cetacean species in the Mediterranean and Black Seas (Domingo et al. 1990, 1992, Aguilar \& Raga 1993, Birkun et al. 1999, Fernández et al. 2008, Gauffier 2008, Raga et al. 2008, Keck et al. 2010, Soto et al. 2011a). During 2006 and 2007 the second (and less severe) DMV epizootic affected long-finned pilot whales Globicephala melas, as well as striped dolphins in Spanish Mediterranean waters (Fernández et al. 2008, Gauffier 2008, Raga et al. 2008). The epizootic started in October 2006 in pilot whales in the Strait of Gibraltar, and spread eastwards and northwards, arriving in the Valencia region and Balearic Islands in April 2007. Infected striped dolphins were found in early July 2007 along the coast of the Valencia region and Catalonia. DMV-affected cetaceans showed systemic infection with pathologic changes similar to those seen in the 1990 epizootic, characterised by bronchiolo-interstitial pneumonia, lymphoid depletion and non-suppurative encephalitis (Domingo et al. 1992, Duignan et al. 1992, Raga et al. 2008, Soto et al. 2011a). Secondary opportunistic infections, such as systemic toxoplasmosis, mycotic respiratory and brain infections, and herpesvirus infections (Domingo et al. 1992, Bellière et al. 2010, Soto et al. $2011 b)$ were associated with the epizootics. In the follow-up to the 1990 epizootic, unusual forms of chronic DMV infection affecting only the central nervous system (CNS) were found in 5 of $27(18.5 \%)$ striped dolphins submitted for necropsy between January 1991 and May 1994 from the Catalonian coast (Domingo et al. 1995). Since 2007, the monitoring of DMV infection has continued, including most coastal areas of the Spanish Mediterranean (Andalusia, Valencia Region and Catalonia), and, again, forms of localised DMV infection restricted to the CNS have been identified. We report here on the epidemiological data available for these cases, the main pathological findings and the molecular diagnosis of this disease.

\section{MATERIALS AND METHODS}

\section{Necropsy and sampling}

From January 2008 to December 2010, 118 Mediterranean striped dolphins Stenella coeruleoalba in a state of good preservation were necropsied, 20 from the Catalonian, 14 from the Valencia region and 84 from Andalusian waters. Location of stranding, body length and sex were recorded for most of the dolphins. Necropsy and sampling were done by local organisations (conservation and research groups) working in these 3 regions. Formalin-fixed, paraffinembedded tissue slides were received from cases in Andalusia; formalin-fixed tissues and some frozen tissues were received from cases in Valencia; whereas cases occurring in Catalonia were necropsied at the Veterinary School of Barcelona; thus, a wide sampling of formalin-fixed, paraffin-embedded samples, as well as frozen tissues conserved at $-20^{\circ} \mathrm{C}$ were available for study. From all these cases, the following organs considered to be targets of DMV infection (Domingo et al. 1992), were available for histopathologic and immunohistochemical (IHC) studies: lung (110/118), lymph nodes (prescapular, lung-associated and/or mesenteric lymph nodes, 105/118) and brain (118/118). Brain sampling locations varied, including the cerebral cortex in 109/118 dolphins, the cerebellar cortex in 93/118 dolphins and other brain sites in 65/118 dolphins. Formalinfixed tissues were embedded in paraffin and routinely processed for histopathology; $4 \mu \mathrm{m}$ sections were prepared, deparaffinised and stained with haematoxylin and eosin.

\section{Immunohistochemistry}

IHC detection of DMV was performed on brain tissue and, when available, also on samples of lung and lymph nodes. A mouse monoclonal antibody against the canine distemper virus nucleoprotein (Ref. NP 050505 VMRD, Pullman, WA, USA), known to react with DMV (Raga et al. 2008), was used as the primary antibody at a dilution of 1:200 in Tris-buffered saline (TBS) with $2 \%$ bovine albumin. The technique was performed as previously described (Raga et al. 2008). Lung sections from a DMV-infected dolphin were used as a positive control in each test. Duplicate tissue sections were also incubated with TBS instead of the primary antibody as a negative control.

\section{Molecular detection of DMV}

Molecular detection of DMV was performed by RTPCR on tissues from 17 dolphins: 6 from Catalonian coasts and 11 from Valencian coasts. From all these cases, the following organs considered to be targets 
of DMV infection (Domingo et al. 1992) were investigated: lung (10/17), lymph nodes (prescapular, pulmonary and/or mesenteric lymph nodes, 12/17) and brain (cerebral cortex, 17/17).

Approximately $1 \mathrm{~g}$ of tissue was homogenised in $10 \mathrm{ml}$ of Dulbecco's modified Eagle's medium (DMEM). The RNA was extracted from tissue homogenates using the RNA viral isolation kit Nucleospin II according to the manufacturer's instructions (Macherey-Nagel Laboratory).

DMV molecular detection was performed by 2 different 1-step RT-PCR techniques that amplified a 429 bp fragment (Barrett et al. 1993) and a 78 bp fragment (Krafft et al. 1995, Saliki et al. 2002), both within the phosphoprotein (P) gene. All the previously frozen samples detailed above were studied using the RT-PCR for the longer fragment. The RTPCR for the $78 \mathrm{bp}$ fragment was only performed in brain tissue from dolphins showing DMV immunopositivity in the brain. One negative control and one positive control of DMV provided by M. Baron (Institute for Animal Health, Pirbright Laboratory, UK) were included.

\section{Statistical analysis}

In order to investigate significant association of IHC-DMV positivity with variables such as sex, length, etc., a descriptive analysis including frequencies and proportions for categorical variables and median and ranges for numerical variables was performed. Univariate analysis was carried out using a Pearson Chi-squared test for categorical variables such as sex, month, year and region of stranding, whereas a non-parametric analysis using a Wilcoxon Mann-Whitney test was applied to compare the body length of Stenella coeruleoalba specimens between the IHCDMV positives and IHC-DMV negatives. Thereafter the effect on morbillivirus positivity of all these factors (i.e. sex, body length, month, year and region of stranding) was assessed using a binary logistic regression model to account for possible remaining confounders or interactions. All the variables with $\mathrm{p}<0.1$ (2-sided) in the univariate analysis were tested further by the model. Variables were excluded from the model using a backward-stepwise approach. Statistical analyses were per- formed using SPSS software Version 17 (Statistical Package for Social Sciences (SPSS) Inc.).

\section{RESULTS}

\section{Epidemiological and pathological findings}

Monitoring by histopathology and immunohistochemistry of stranded and necropsied striped dolphins Stenella coeruleoalba in the period from 2008 to 2010 showed DMV infection in 32 out of 118 $(27.1 \%)$ dolphins, with the first affected dolphin found stranded in Andalusia in May 2008. DMV-antigen and DMV-related lesions were restricted solely to the CNS. The distribution, by provincial administrative divisions, of strandings and DMV-infected dolphins is shown in Fig. 1. The percentage of DMV cases in Andalusia was 27.4, on the Valencia region coast was 28.6 and in Catalonia was 25.0. The proportion of positives did not differ significantly among regions. The annual incidence for these 3 regions is shown in Table 1. The number of positive animals seemed to decrease in 2010 compared to 2008 and 2009; however, this trend was not statistically significant ( $\mathrm{p}=0.311)$, which was probably due to the small sample size in 2010 .

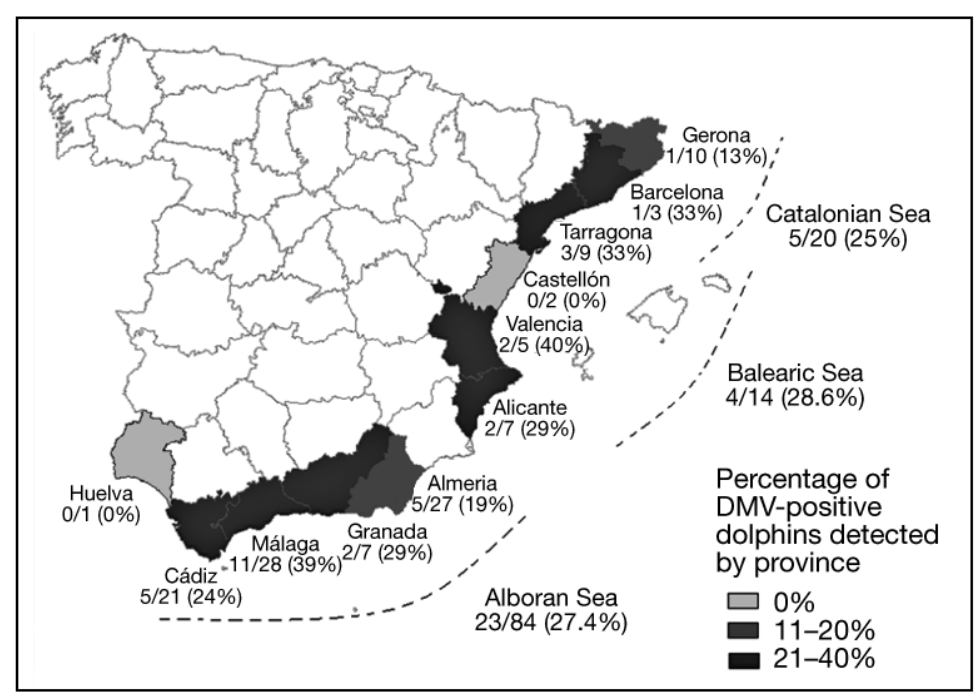

Fig. 1. Stenella coeruleoalba. Spatial distribution of total and positive striped dolphins immunohistochemically tested for dolphin morbillivirus (DMV) between 2008 and 2010 on Spanish Mediterranean coasts. The percentages of DMV-positivity detected by province are presented in brackets. The Catalonian coast includes the littoral of Gerona, Barcelona and Tarragona provinces; the Valencia region includes the littoral of Castellón, Valencia and Alicante provinces and Andalusian waters include the littoral of Almería, Granada, Málaga, Cádiz and Huelva provinces 
Table 1. Stenella coeruleoalba. Summarised data of the striped dolphins necropsied in the Spanish Mediterranean littoral between 2008 and 2010, by region and by year. Each cell represents the number of immunohistochemistry-positive dolphins out of the total number of dolphins tested. The percentage of positive cases is included in brackets

\begin{tabular}{|lcccc|}
\hline Location & 2008 & 2009 & 2010 & Total \\
\hline Andalusia & $11 / 33(33.3)$ & $9 / 30(30.0)$ & $3 / 21(14.3)$ & $23 / 84(27.4)$ \\
Valencian region & $2 / 5(40.0)$ & $2 / 6(33.3)$ & $0 / 3(0.0)$ & $4 / 14(28.6)$ \\
Catalonia & $2 / 12(16.7)$ & $2 / 6(33.3)$ & $1 / 2(50.0)$ & $5 / 20(25.0)$ \\
Total & $15 / 50(30.0)$ & $13 / 42(31.0)$ & $4 / 26(15.4)$ & $32 / 118(27.1)$ \\
\hline
\end{tabular}

The sex was recorded for 112 dolphins, of which 61 $(54.5 \%)$ were males and $51(45.5 \%)$ females. From these individuals, $20 \%$ of the males and $27 \%$ of the females were positive for DMV according to IHC. These proportions did not show significant differences at the $5 \%$ level of significance $\left(\chi^{2}=0.058\right.$; $\mathrm{p}=0.810$ )

The median length of IHC-DMV-negative dolphins was $160.5 \mathrm{~cm}$ (with a range between 70.0 and $225.0 \mathrm{~cm}$ ), whereas the median length of IHC-DMVpositive dolphins was $196.5 \mathrm{~cm}$ (with a range between 123.0 and $290.0 \mathrm{~cm}$ ). On the basis of the results of the Wilcoxon Mann-Whitney test calculated, the IHC-DMV-positive striped dolphins were longer than the negative dolphins, and this difference could be statistically inferred at the $5 \%$ level with a $\mathrm{p}<0.001$.

With the aim of describing the relationship between all the explanatory variables considered (i.e. sex, month, length, region and year) and the DMV immunopositivity, further analysis was performed using a binary logistic regression model. In concurrence with the previous results obtained by univariate analysis, of all explanatory variables included in the model, only body length could be associated with the presence of the chronic lesions caused by DMV $(p<0.05)$.

Primary histopathological findings were limited to the brain, and consisted of multifocal, bilaterally asymmetrical, non-suppurative meningoencephalitis (Fig. 2) of variable intensity, with mononuclear perivascular cuffs, gliosis and glial nodules with neuronophagia, and spongiosis. In general, white matter was affected only mildly, but spongiosis and gliosis were evident in those regions immediately beneath the most affected grey matter. Cytoplasmic or nuclear eosinophilic inclusions were occasionally detected. Syncytial cells were not observed. DMV immunolabelling was found only in the CNS; systemic morbilliviral infection, as observed during epizootics, was not observed in any of the dolphins examined in the 2008 to 2010 period. DMV nucleoprotein antigen was found in neuronal perikarya, axons and dendritic processes, and occasionally in glial cells. Staining in the neocortex was stronger in the deeper layers, highlighting many pyramidalshaped neurons (Fig. 3); the staining intensity was not distributed evenly among the different circumvolutions. Positive staining was also found in glial cells. In the white matter, positivity was confined to axons (occasionally dystrophic) and glial cells

\section{RT-PCR results}

Frozen samples from 6 IHC-DMV-positive and 11 IHC-DMV-negative dolphins stranded between 2008 and 2010 were investigated by RT-PCR for DMV. A specific $429 \mathrm{bp}$ P gene fragment was amplified from brain tissue in 3 out of the 6 IHC-DMV-positive dolphins. IHC-DMV-negative dolphins and non-nervous tissues were negative in all cases. Surprisingly, no band was detected through RT-PCR of the brain of the 3 IHC-DMV-positive dolphins, in spite of strong immunostaining and the absence of autolysis. A second RT-PCR targeting a smaller fragment of $78 \mathrm{bp}$ within the $\mathrm{P}$ gene was positive in the brain samples of all 6 IHC-DMV-positive dolphins, confirming the presence of DMV nucleic acid in all these cases.

\section{DISCUSSION}

The Mediterranean Sea provides a unique epidemiological environment regarding morbillivirus circulation in cetaceans, with 2 DMV epizootics 16 yr apart (Domingo et al. 1990, Raga et al. 2008, Keck et al. 2010, Soto et al. 2011a). Available evidence suggests that DMV has not circulated in Stenella coeruleoalba between the 2 epizootics (Soto et al. 2011a), and it appears that DMV has not established itself in an endemic infection cycle in the western Mediterranean striped dolphin population. The decline in the proportion of seropositive dolphins in the years following the 1990 epizootic (Van Bressem et al. 2001) is consistent with this view. Therefore, at least in the western Mediterranean Sea, systemic DMV cases in S. coeruleoalba occurred from July to December after the beginning of the epizootic, and we consider that the epizootic faded out along the 


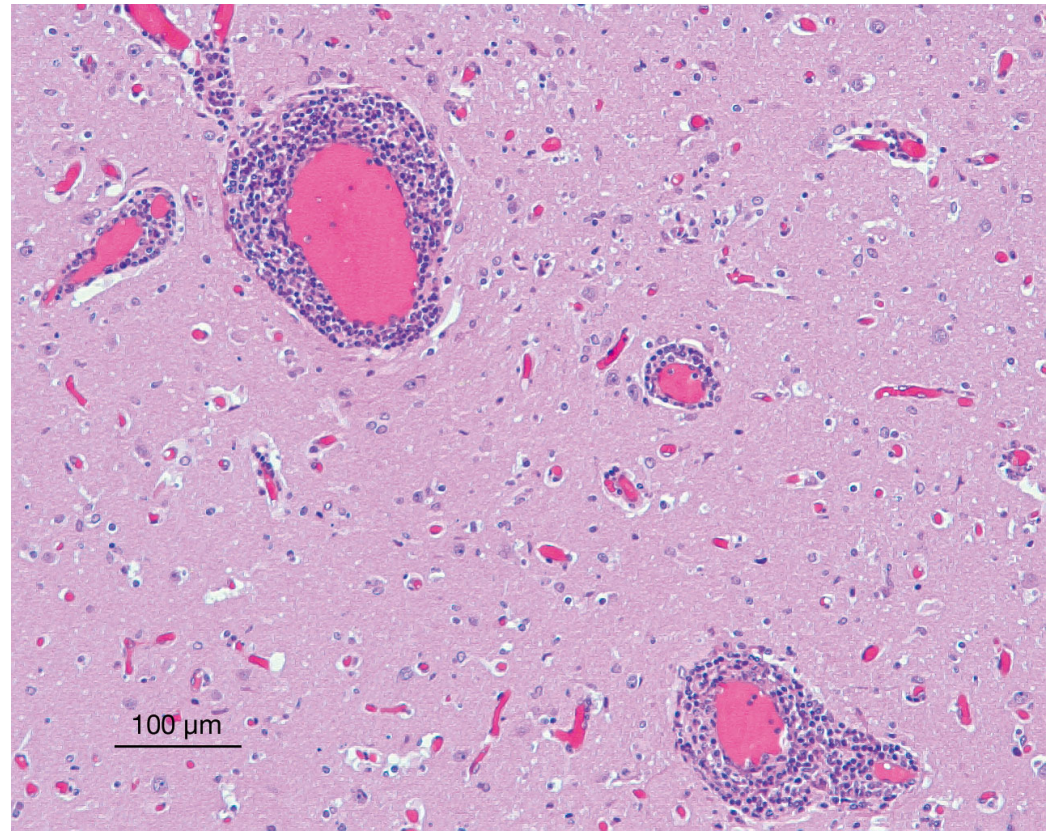

Fig. 2. Stenella coeruleoalba. Haematoxylin and eosin stain of the caudate nucleus of Case N-779/10. Encephalitis with non-suppurative perivascular cuffs and increased glial cell numbers

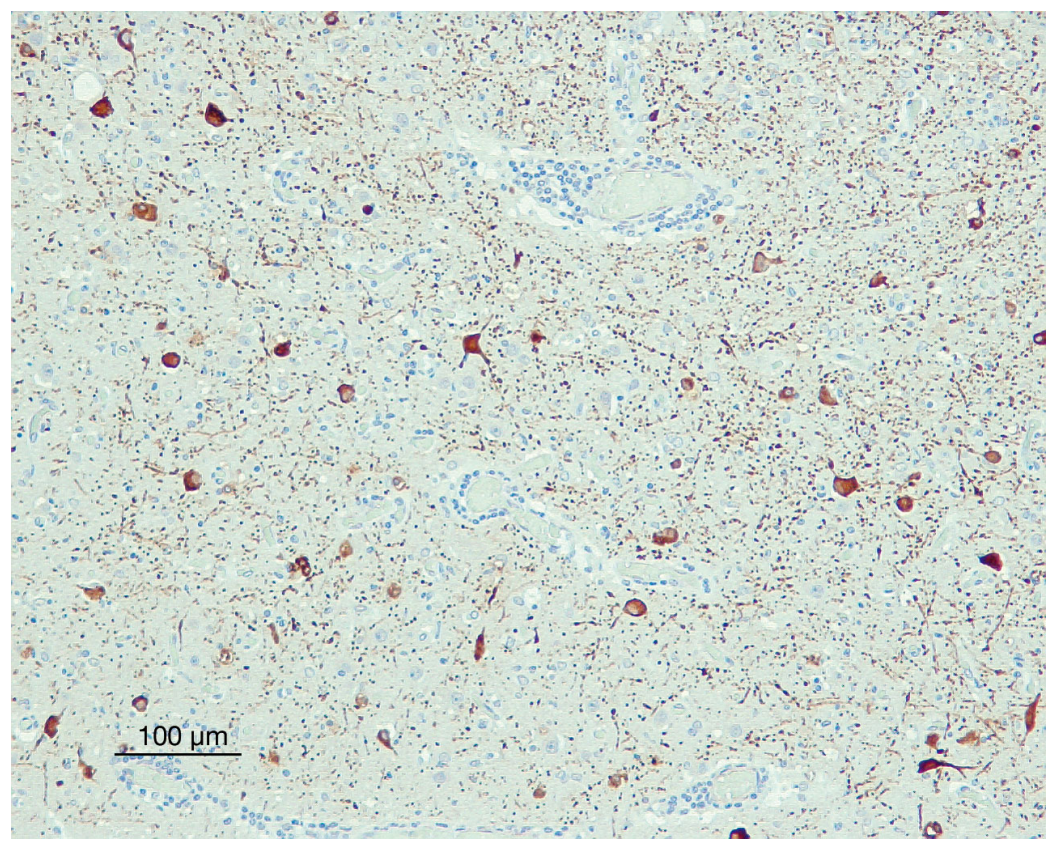

Fig. 3. Stenella coeruleoalba. Immunostaining against dolphin morbillivirus (DMV) in a serial slide of the same area shown in Fig. 2. Note the massive presence of DMV antigen within the neuronal pericaria. The cell nuclei were not always stained. The punctate staining in the neuropile corresponds to dendrites and axons. The $429 \mathrm{bp}$ RT-PCR for the phosphoprotein (P) gene in brain tissue was negative in this case, in spite of strong immunostaining and the absence of autolysis. A second RT-PCR targeting a smaller fragment (78 bp) within the $\mathrm{P}$ gene was positive in this brain sample
Catalonian coast in December 2007 (Soto et al. 2011a).

Similar to the previous epizootic in the Mediterranean Sea (Domingo et al. 1995), the data presented here show that the 2007 epizootic was followed by the occurrence of localised forms of DMV infection restricted to the CNS.

These cases have been recognised through intensive monitoring and a clear chronological separation of systemic and CNS-localised forms of the disease. Therefore, we believe that morbillivirus infection in Mediterranean striped dolphins can occur in 2 different forms: (1) systemic cases, probably of a more acute nature, associated with massive die-offs during the epizootic period and characterised by systemic lesions (bronchiolointerstitial pneumonia, lymphoid depletion and non-suppurative encephalitis, with DMV-immunopositivity in all affected organs) and (2) CNSlocalised cases, subacute or chronic in nature, found stranded in the months to years following the epizootic. These cases characteristically showed brain inflammatory lesions, with the presence of DMV restricted to the brain. The absence of virus in other organs considered target tissues for DMV in epizootics, such as lung or lymph nodes, was confirmed by investigation of these organs with RT-PCR. The fact that non-nervous tissues were spared in these chronic cases suggests that DMV is not excreted and, therefore, that dolphins affected by this form of DMV disease do not transmit the virus to other marine mammals.

Since 2007 the monitoring of epizootics has been improved, including IHC-DMV detection and RT-PCR, and also has been extended to cover a larger geographic area, including not only Catalonian strandings (as in 1990), but also strandings from Andalusia and the Valencia region, comprising almost the whole Spanish Mediterranean coast. This has allowed us to show that the occurrence of DMV- 
CNS-restricted cases is a widespread phenomenon in the western Mediterranean Sea and not a geographically restricted event. This extended monitoring has also allowed us to measure the global impact of this localised form of DMV disease in the Spanish Mediterranean striped dolphin population, which was found in $27.1 \%$ of the necropsied and investigated dolphins in the first $3 \mathrm{yr}$ period after the epizootic; this represents an added mortality of $37 \%$ over the background mortality without DMV. The proportion of cases apparently declined in 2010, with respect to the 2 previous years, and if occurrence of DMV-CNS-localised cases follows the same temporal pattern as after the 1990 epizootic, it is to be expected that no further cases will be detected after 2012. This form of the DMV disease constitutes the most relevant single cause of stranding and death in Mediterranean striped dolphins along the Spanish coast in the years following a DMV epizootic, and, in the long term, it might even surpass the effects of the epizootic itself; this appeared to be true for 2007 at least.

There are some similarities between this form of DMV-CNS localised disease and subacute sclerosing panencephalitis (SSPE) in humans. SSPE is a rare chronic and fatal disease in humans, which is caused by a replicative defective measles virus (MV); after infection early in life it persists in a latent form in the CNS (Connolly et al. 1967, Garg 2008). The infection is reactivated several years (2 to $10 \mathrm{yr}$ ) after the primary infection, causing fatal nervous lesions. A similar type of chronic latent infection has also been identified in dogs, known as old dog encephalitis (ODE), caused by an equally replicative defective canine distemper virus (CDV). Both SSPE and ODE are very rare diseases (Garg 2008, Headley et al. 2009). In striped dolphins, we hypothesize that a temporal and pathogenic pattern occurs similar to that found in SSPE and ODE. DMV-CNS-localised cases are derived from non-lethal infections taking place during the epizootic, and the virus remains latent in the brain for months to years before reactivation. Factors leading to the reactivation of CNS-morbilliviral infection are still unknown in humans, dogs and dolphins. Analogous to SSPE, DMV was absent in non-nervous tissues in our study, and, as in SSPE, horizontal transmission does not seem to occur.

Some differences exist between the epidemiology of SSPE and the DMV-CNS-localised disease found in Stenella coeruleoalba. First, the higher risk for males found in SSPE, with a male:female ratio of 2:1 (Halsey et al. 1980, Garg 2008), is not seen in striped dolphins, in which males and females are found to be equally affected by chronic forms of DMV-CNS. Sec- ondly, the incidence of DMV-CNS-localised disease in dolphins seems to be very high compared to that of SSPE in humans. In striped dolphins, an epizootic event might cause thousands of new infections in a short period of time within a specific area, thus leading to the occurrence of a much higher incidence of DMV-CNS-localised disease in dolphins in the years following an epizootic event. In humans, SSPE is estimated to occur at a proportional morbidity rate of 4 to 11 cases of SSPE per 100000 cases of measles (Campbell et al. 2007). The striped dolphin population has been estimated in central Spanish Mediterranean waters during the period from 2001 to 2003 to be 15778 individuals (95\% CI = 10940 to 22756 ) by line transect sampling (Gómez de Segura et al. 2006) and 16892 animals (CV $=0.16$ ) by spatial modelling methods (Gómez de Segura et al. 2007). In a hypothetical scenario according to which the whole population would have been exposed to DMV in the last epizootic, the proportional morbidity rate of DMVCSN-localised infection in dolphins for the first striped dolphin abundance estimation would be equivalent to 141 and 293 cases per 100000 cases. A possible explanation for this difference could be that the striped dolphin shows a higher predisposition than other species for suffering chronic latent DMV infections in nervous tissue. Testing of this hypothesis is, however, hampered by the profound lack of knowledge on the pathogenesis and triggering factors of this disease in dolphins. In humans, the incidence of SSPE is higher in children infected by MV at an early age (Jabbour et al. 1972), and a possible role of maternal antibodies has been hypothesized for this increased risk, due to the fact that the antibodies appear to generate persistent infection and modulate acute infection in vitro in cell cultures (Fujinami \& Oldstone 1979, Schneider-Schaulies et al. 1992). However, direct evidence for this suggestion is lacking (Rima \& Duprex 2005).

From our study, the only risk factor for DMV-CNSlocalised disease in striped dolphins appears to be the body length of the animals, with affected dolphins being longer (thus older) than non-affected ones. We are not able to offer an explanation for this finding. One hypothesis would be that dolphins with a residual, weak immune response to DMV resulting from the first epizootic in 1990 could be more susceptible to developing DMV-CNS-localised disease when confronted with the virus on a second occasion.

If SSPE-like disease occurs in dolphins, mutations and/or deletions similar to those described for SSPEMV strains may be found in DMV. In SSPE, major changes have been found in the P, M, F and H genes, 
in the form of mutations and deletions that alter the functionality of these proteins (Cattaneo et al. 1989, Wong et al. 1989, Schmid et al. 1992, Hirano et al. 1993, Garg 2008). Interestingly, 3 of 6 of our DMVCNS-localised cases were negative according to a RT-PCR targeting a $429 \mathrm{bp}$ fragment of the P gene (Barrett et al. 1993), but were positive with another RT-PCR targeting a much smaller fragment of $78 \mathrm{bp}$ (Krafft et al. 1995, Saliki et al. 2002). Whether this is due to a mismatching of a primer or to deletions on the gene is unknown, but clearly contraindicates the use of any RT-PCR protocol based on RT-PCR targeting the $429 \mathrm{bp}$ described by Barrett et al. (1993) to detect this specific form of DMV disease. Sequencing of DMV-CNS-localised cases in dolphins and comparison of obtained sequences with those published for DMV isolated from systemic cases during the epizootics will reveal whether the changes present in the sequence of SSPE-MV are also found in DMVCNS-localised cases. This work is in progress in our laboratory.

Acknowledgements. The authors thank J. Tarradas, R. Rivas and M. Muñoz from CRESA (Centre de Recerca en Sanitat Animal) for their technical support, and M. Sharp for critical review of the manuscript. Samples from Andalusia were kindly provided by Conserjería de Medio Ambiente, Junta de Andalucía (Spain). J.A.R. was supported by a Prometeo 2011/40 project of the Conselleria de Educacio and the Conselleria de Medi Ambient, Aigua, Territori i Habitatge (Generalitat Valenciana).

\section{LITERATURE CITED}

Aguilar A, Raga JA (1993) The striped dolphin epizootic in the Mediterranean Sea. Ambio 22:524-528

Barrett T, Visser IK, Mamaev L, Goatley L, Van Bressem MF, Osterhaust AD (1993) Dolphin and porpoise morbilliviruses are genetically distinct from phocine distemper virus. Virology 193:1010-1012

Bellière EN, Esperón F, Arbelo M, Muñoz MJ, Fernández A, Sánchez-Vizcaíno JM (2010) Presence of herpesvirus in striped dolphins stranded during the cetacean morbillivirus epizootic along the Mediterranean Spanish coast in 2007. Arch Virol 155:1307-1311

Birkun A, Kuiken JRT, Krivokhizdin S, Haines DM and others (1999) Epizootic of morbilliviral disease in common dolphins (Delphinus delphis ponticus) from the Black Sea. Vet Rec 144:85-92

- Campbell H, Andrews N, Brown KE, Miller E (2007) Review of the effect of measles vaccination on the epidemiology of SSPE. Int J Epidemiol 36(6):1334-1348

Cattaneo R, Schmid A, Spielhofer P, Kaelin K and others (1989) Mutated and hypermutated genes of persistent measles viruses which caused lethal human brain diseases. Virology 173:415-425

Connolly JH, Allen IV, Hurwitz LJ, Millar JHD (1967) Measles virus antibody and antigen in subacute sclerosing panencephalitis. Lancet 289:542-544
Domingo M, Ferrer L, Pumarola M, Marco A and others (1990) Morbillivirus in dolphins. Nature 348:21

Domingo M, Visa J, Pumarola M, Marco AJ, Ferrer L, Rabanal R, Kennedy S (1992) Pathologic and immunocytochemical studies of morbillivirus infection in striped dolphins (Stenella coeruleoalba). Vet Pathol 29:1-10

- Domingo M, Vilafranca M, Visa J, Prats N, Trudgett A, Visser I (1995) Evidence for chronic morbillivirus infection in the Mediterranean striped dolphin (Stenella coeruleoalba). Vet Microbiol 44:229-239

Duignan PJ, Geraci JR, Raga JA, Calzada N (1992) Pathology of morbillivirus infections in striped dolphins (Stenella coeruleoalba) from Valencia and Murcia, Spain. Can J Vet Res 56:242-248

> Fernández A, Esperón F, Herráez P, Espinosa de los Monteros A and others (2008) Morbillivirus and pilot whale deaths, Mediterranean Sea. Emerg Infect Dis 14:792-794

Fujinami RS, Oldstone MB (1979) Antiviral antibody reacting on the plasma membrane alters measles virus expression inside the cell. Nature 279:529-530

Garg RK (2008) Subacute sclerosing panencephalitis. J Neurol 255:1861-1871

Gauffier P (2008) Estimating the consequences of the 2006-07 morbillivirus epizootic on long-finned pilot whales in the strait of Gibraltar. MS dissertation, Centre National de la Recherche Scientifique-Centre d'Etudes Biologiques de Chizé, Beauvoir-Sur-Niort

> Gómez de Segura A, Crespo EA, Pedraza SN, Hammond PS, Raga JA (2006) Abundance of small cetaceans in the waters of the central Spanish Mediterranean. Mar Biol 150:149-160

> Gómez de Segura A, Hammond PS, Cañadas A, Raga JA (2007) Comparing cetacean abundance estimates derived from spatial models and design-based line transect methods. Mar Ecol Prog Ser 329:289-299

> Halsey NA, Modlin JF, Jabbour JT, Dubey L, Eddins DL, Ludwig DD (1980) Risk factors in subacute sclerosing panencephalitis: a case-control study. Am J Epidemiol 111:415-424

$>$ Headley SA, Amude AM, Alfieri AF, Bracarense APFRL, Alfieri AA, Summers BA (2009) Molecular detection of canine distemper and the immunohistochemical characterization of the neurologic lesions in naturally occurring old dog encephalitis. J Vet Diagn Invest 21:588-597

> Hirano A, Ayata M, Wang AH, Wong TC (1993) Functional analysis of matrix proteins expressed from cloned genes of measles virus variants that cause subacute sclerosing panencephalitis reveals a common defect in nucleocapsid binding. J Virol 67:1848-1853

> Jabbour JT, Duenas DA, Sever JL, Krebs HM, HortaBarbosa L (1972) Epidemiology of subacute sclerosing panencephalitis (SSPE). A report of the SSPE registry. JAMA 220:959-962

Keck N, Kwiatek O, Dhermain F, Dupraz F and others (2010) Resurgence of morbillivirus infection in Mediterranean dolphins of the French coast. Vet Rec 166:654-655

Krafft A, Lichy JH, Limpscomb TP, Klaunberg BA, Kennedy S, Taubenberger JA (1995) Postmortem diagnosis of morbillivirus infection in bottlenose dolphins (Tursiops truncatus) in the Atlantic and Gulf of Mexico epizootics by polymerase chain reaction-based assay. J Wildl Dis 31: 410-415

Raga JA, Banyard A, Domingo M, Corteyn M and others (2008) Dolphin morbillivirus epizootic resurgence, Mediterranean Sea. Emerg Infect Dis 14:471-473 
Rima BK, Duprex WP (2005) Molecular mechanism of measles virus persistence. Virus Res 111:132-147

Saliki JT, Cooper EJ, Gustavson JP (2002) Emerging morbillivirus infections of marine mammals: development of two diagnostic approaches. Ann NY Acad Sci 969: 51-59

Schmid A, Spielhofer P, Cattaneo R, Baczko K, ter Meulen V, Billeter MA (1992) Subacute sclerosing panencephalitis is typically characterized by alterations in the fusion protein cytoplasmic domain of the persisting measles virus. Virology 188:910-915

Schneider-Schaulies S, Liebert UG, Segev Y, Rager-Zisman B, Wolfson M, ter Meulen V (1992) Antibody-dependent transcriptional regulation of measles virus in persistently infected neural cells. J Virol 66:5534-5541

Editorial responsibility: Michael Moore,

Woods Hole, Massachusetts, USA
Soto S, González R, Alegre F, González B and others (2011a) The 2007 dolphin morbillivirus epizootic in the Mediterranean Catalonian coast. Vet Rec 169:102

Soto S, González B, Willoughby K, Maley M and others (2011b) Systemic herpesvirus and morbillivirus co-infection in a striped dolphin (Stenella coeruleoalba). J Comp Pathol (in press)

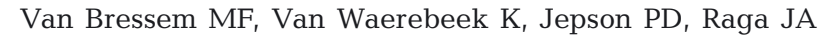
and others (2001) An insight into the epidemiology of dolphin morbillivirus worldwide. Vet Microbiol 81:287-304

Wong TC, Ayata M, Hirano A, Yoshikawa Y, Tsuruoka H, Yamanouchi K (1989) Generalized and localized biased hypermutation affecting the matrix gene of a measles virus strain that causes subacute sclerosing panencephalitis. J Virol 63:5464-5468

Submitted: April 28, 2011; Accepted: June 27, 2011

Proofs received from author(s): September 15, 2011 